\title{
Retroviruses in rheumatic diseases
}

The aetiology of rheumatoid diseases is unclear but may be multifactorial, the result of complex interactions between environmental, neuroendocrinological, and genetic factors. Whilst several viruses (for example cytomegalovirus, Epstein-Barr virus, rubella virus and parvovirus B19 are associated with self limiting arthritic episodes, retroviruses have been suggested as aetiological agents of rheumatic diseases. Several excellent articles ${ }^{12}$ have provided convincing evidence that both exogenous and endogenous retroviruses are involved, but recent negative observations should not be ignored.

Exogenous retroviruses include lentiviruses such as human immunodeficiency virus (HIV-1), which cause rheumatological manifestations, and oncoviruses such as human $\mathrm{T}$ cell lymphotrophic virus (HTLV-I), which induce tumour formation and are associated with chronic inflammatory arthropathy. ${ }^{3}$ In animals, lentiviruses such as maedi-visna virus and caprine arthritis-encaphalitis virus, produce arthritis in sheep and goats, respectively, and an exocrinopathy that resembles primary Sjögren's syndrome has been described in mice transgenic for the HTLV-I tax (transactivating) gene. Endogenous retroviruses are transmitted vertically, through germline DNA, and resemble infectious primate and murine retroviruses in their genetic morphology. Human endogenous retroviruses (HERVs) constitute $0 \cdot 1-0.6 \%$ of human DNA and have been divided into 16 families with copy numbers ranging from 1 to 10000 copies per haploid genome. ${ }^{4}$ Interest in their role in autoimmune disease has been stimulated by work on the murine lupus model, in which the affected animals express an endogenous $8.4 \mathrm{~kb}$ retroviral transcript. ${ }^{5}$

Serological studies in human rheumatic diseases have provided, at best, circumstantial evidence. A recent study ${ }^{6}$ with adequate controls has unequivocally demonstrated antibodies reactive with retroviral proteins in a minority of patients with rheumatoid arthritis, polymyositis, and systemic lupus erythematosus. The observations could not be accounted for by rheumatoid factor and polyclonal $\mathbf{B}$ cell activation. Similarly, others reported patients with antibodies to retroviral products either in the sera, or at the site of disease. ${ }^{78}$ However, some reports ${ }^{9}{ }^{10}$ negate these findings. Unfortunately, consensus of a clear assessment of the serological evidence is restricted by differences in assay systems and in ethnographic groups. However, common to those favouring a retroviral involvement, is the presence of antibodies to retroviral products in a subset of patients.

Molecular investigations have demonstrated extrinsic DNA that shows sequence homology with HIV-1, in immune complexes in the plasma of a patient with systemic lupus erythematosus. ${ }^{11}$ Whilst this evidence is of interest, another similar study detected only DNA having sequence homology with bacterial antigens. ${ }^{12}$ More convincing evidence of retroviral involvement in rheumatological diseases has been sought using the polymerase chain reaction (PCR) to identify or exclude candidate retroviral agents in peripheral blood mononuclear cells (PBMCs) and at sites of disease. However, recent studies ${ }^{6}{ }^{13}$ using single-round PCR with consensus oligonucleotide primers, have shown no evidence of the exogenous retroviruses HIV-1 and HTLV-I. Similarly, testing of genomic DNA from synovial cells of patients with early and established RA did not yield specific viral product when using degenerate primers for lentiviruses, ${ }^{14}$ and PCR of complementary DNA from synovial cells failed to amplify lentiviral transcripts. It is worth noting that the degenerate primers used in this study were unable to recognise endogenous retroviruses.

Endogenous retroviruses are generally stable genetic elements, but may transpose, resulting in new integrations within or near a gene, thereby altering its expression: this phenomenon is shared by a number of murine endogenous retroviruses $^{15}$ and could be relevant to the induction or perpetuation of autoimmunity. Furthermore, the expression or recognition of endogenous retroviral sequences might explain both the familial aggregation of autoimmune diseases and the detection of cross reactive antiretroviral antibodies. A transcriptionally active human endogenous retrovirus, HRES-1, has been described which is capable of protein expression. This endogenous retrovirus shows homology with the gag protein of HTLV-I, and sera from primary Sjögren's syndrome and systemic lupus erythematosus appear to contain significantly greater HRES-1 peptide binding activity than sera of normal donors. ${ }^{16}$ This suggests that the HRES-1 $28 \mathrm{kDa}$ protein may serve as an autoantigen, eliciting autoantibodies cross reactive with HTLV antigens. What of the role of other HERVs? Overall, the picture appears far from simple. Northern analysis of PBMCs from patients with autoimmune muscle disease and from healthy blood donors demonstrates that most people express RNA from multiple classes of HERV and that the expression is heterogenous. ${ }^{17}$ Furthermore, the expression of several classes of HERV appears to be coordinately regulated, with more complex changes in HERV expression occurring with activation of PBMCs with mitogens. A more specific and sensitive approach is reverse transcription polymerase chain reaction (RT-PCR). This technique has shown a similar amplification pattern of HERVs from PBMCs of seven normal donors. ${ }^{18}$ In addition, sequencing of cloned amplification products reveals homology with RTVL-H, HERV-E, and HERV-K. Evidently, these endogenous retroviruses are expressed in healthy individuals; but what about in rheumatoid diseases? Interestingly, RT-PCR titration shows no difference in the levels of expression of HERV-K and RTVL-H in rheumatoid arthritis; polymoysitis, and normals individuals (personal observation). Clearly, other HERVs need investigation.

The involvement of retroviruses in the pathogenesis of rheumatoid diseases is further indicated from cell culture work in which a retrovirus like particle (VLP) has been detected in a human $\mathrm{T}$ cell line cocultured with salivary gland tissue from a patient with primary Sjögren's syndrome. In addition, a VLP in cells cultured from a rheumatoid arthritis synovial fluid has shown close homology to retroviral type $C$ particles, though it lacks the typical morphological and immunological properties of human retroviruses. ${ }^{19}$

Despite these findings, there is still much work to be done in this intriguing area of research and, clearly, an unbiased view for the role of retroviruses in rheumatoid diseases must be maintained. Understanding the interactions of retroviruses with helper viruses and protooncogenes, and the use of RT-PCR with broad spectrum oligonucleotide retroviral primers ${ }^{20}$ could yield further useful evidence. 
1 Mountz J D, Talal N. Retroviruses, apoptosis and autogenes. Immunology Today 1993; 14: 532-6.

2 Kalden J R, Gay S. Retroviruses and autoimmune rheumatic diseases. Clin Exp Immunol 1994; 98: 1-5.

3 Nishioka K, Maruyama I, Sato K, Kitajima I, Nakajima Y, Osame M. Chronic inflammatory arthropathy associated with HTLV-I. Lancet 1989 i: 441 .

4 Krieg A M, Gourley M F, Perl A. Endogenous retroviruses: potential etiologic agents in autoimmunity. FASEB $\mathcal{f} 1992 ; 6: 2537-44$

5 Krieg A M, Steinberg A D, Khan A S. Increased expression of novel fulllength endogenous MCF-related transcript in autoimmune mouse strains. Virology 1988; 162: 274-6.

6 Nelson P N, Lever A M L, Bruckner F E, Isenberg D A, Kessaris N, Hay F C. Polymerase chain reaction fails to incriminate exogenous retroviruses HTLV-I and HIV-1 in rheumatological diseases although a minority of sera cross react with retroviral antigens. Ann Rheum Dis 1994; 53: 749-54.

7 Eguchi K, Matsuoka N, Ida H, et al. Primary Sjögren's syndrome with antibodies to HTIV-I: clinical and laboratory features. Ann Rheum Dis 1992; 51: 769-76.

8 Ziegler B, Gay R E, Huang G, Fassbender H, Gay S. Immunohistochemical localization of HTLV-I p19- and p24-related antigens in synovial joints of patients with rheumatoid arthritis. Am f Pathol 1989 135: $1-5$.

9 Pelton B K, North M, Palmer R G, et al. A search for retrovirus infection in systemic lupus erythematosus and rheumatoid arthritis. Ann Rheum Dis 1988; 47: 206-9.

10 Lolli F, Ernerudh J, Kam-Hansen S, Link H. No association between antibodies to HTLV-I and polymyositis, rheumatoid arthritis and SLE. Scand $\mathcal{f}$ Rheumatol 1987; 16: 213-5.
11 Kalden J R, Winkler T, Krapf F. Are retroviruses involved in the aetiology of rheumatic diseases? Br $\mathcal{F}$ Rheumatol 1991; 30 (suppl): 63-9.

12 Terada K, Okuhara E, Kawarada Y, Hirose S. Demonstration of extrinsic DNA from immune complexes in plasma of a patient with systemic lupus erythematosus. Biochem Biophys Res Commun 1991; 174: 323-30.

13 Nelson P N, Bowman S J, Hay F C, Lanchbury J S, Panayi G S, Lever A M L. Absence of exogenous retroviruses in Felty's syndrome. $B$ $f$ Rheumatol 1995. In press.

14 Di Giovine F, Bailly S, Bootman J, Almond N, Duff G W. Absence of lentiviral and human $T$ cell leukemia viral sequences in patients with rheumatoid arthritis. Arthritis Rheum 1994; 37: 349-58.

15 Stoye J, Coffin J. Endogenous retroviruses. In: Weiss R, Teich $\mathrm{N}$, Varmus $\mathrm{H}$, Coffin J, eds. RNA tumor viruses, Vol 2. New York: Cold Spring Harbor Laboratory, $1985 ; 357-404$

16 Brookes S M, Pandolfino Y A, Mithcell T J, et al. The immune response to and expression of cross-reactive retroviral gag sequences in to and expression of cross-reactive retroviral gag

17 Krieg A M, Gourley M F, Klinman D M, Perl A, Steinberg A D. Heterogeneous expression and coordinate regulation of endogenous retroviral sequences in human peripheral blood mononuclear cells. AIDS Res Hum Retroviruses 1992; 8: 1991-8.

18 Medstrand P, Lindeskog M, Blomberg J. Expression of human endogenous retroviral sequences in peripheral blood mononuclear cells of healthy individuals. $\mathcal{F}$ Gen Virol 1992; 73: 2463-66.

19 Stansky G, Vernon J, Aicher W K, Moreland L W, Gay R E, Gay S. Viruslike particles in synovial fluids from patients with rheumatoid arthritis. $\mathrm{Br}$ f Rheumatol 1993; 22: 1044-8.

20 Herrmann M, Kalden J R. PCR and reverse dot hybridization for the detection of endogenous retroviral transcripts. $\mathcal{F}$ Virol Methods 1994; 46: 333-48. 